\title{
A polymicrobial biofilm model for testing the antimicrobial potential of a nisin-biogel for canine periodontal disease control
}

\author{
Eva Cunha $^{* \dagger} \mathbb{D}$, Sandra Rebelo ${ }^{\dagger}$, Carla Carneiro, Luís Tavares, Luís Miguel Carreira and Manuela Oliveira
}

\begin{abstract}
Background: Periodontal disease (PD) in dogs is prompted by the establishment of a polymicrobial biofilm at the tooth surface and a subsequent host inflammatory response. Several strategies may be used for PD control, including dental hygiene home care procedures, like toothbrushing, special diet and chew toys that reduce dental plaque accumulation, or professional periodontal treatments. Aiming at PD control, a biogel composed by nisin and guar-gum was previously developed. This work aimed to establish an in vitro model mimicking the PD-associated biofilms and to evaluate the nisin-biogel inhibitory activity against this polymicrobial biofilm by determining its Minimum Biofilm Inhibitory (MBIC) and Eradication Concentrations (MBEC). Bacterial species tested included Neisseria zoodegmatis CCUG 52598T, Corynebacterium canis CCUG 58627T, Porphyromonas cangingivalis DSMZ VPB 4874, Peptostreptococcus canis CCUG 57081 and an Enterococcus faecalis isolate belonging to a collection of oral bacteria obtained from dogs with PD. Before establishing the biofilm, coaggregation between species was determined by optical density measurement after 2 and 24 hours. Nisin-biogel MBIC and MBEC values regarding the polymicrobial biofilm were determined using a modified version of the Calgary biofilm pin lid device, after confirming the presence of the five bacterial species by Fluorescent In Situ Hybridization.

Results: Only 40\% of the bacterial dual suspensions were able to coaggregate at 2 hours, but all species tested exhibited a coaggregation percentage higher than $30 \%$ at 24 hours. It was possible to establish a $48 \mathrm{~h}$ polymicrobial biofilm model composed by the five bacterial species selected. This model was used to determine nisin-biogel MBIC $(26.39 \pm 5.89 \mu \mathrm{g} / \mathrm{mL})$ and MBEC $(62.5 \pm 27.73 \mu \mathrm{g} / \mathrm{mL})$ values.

Conclusions: Our results showed that the nisin-biogel can inhibit and eradicate PD multispecies biofilms. As this in vitro model mimics an in vivo periodontal polymicrobial biofilm, our results reinforce the potential of the application of nisin-biogel for canine PD control.
\end{abstract}

Keywords: Periodontal disease, Polymicrobial biofilm, Fluorescent In situ Hybridization, Nisin-biogel

\footnotetext{
* Correspondence: evacunha@fmv.ulisboa.pt

${ }^{\dagger}$ Eva Cunha and Sandra Rebelo contributed equally to this work.

CIISA-Centro de Investigação Interdisciplinar em Sanidade Animal, Faculdade de Medicina Veterinária, Universidade de Lisboa, Avenida da Universidade Técnica, 1300-477 Lisboa, Portugal
}

C C The Author(s). 2020 Open Access This article is licensed under a Creative Commons Attribution 4.0 International License, which permits use, sharing, adaptation, distribution and reproduction in any medium or format, as long as you give appropriate credit to the original author(s) and the source, provide a link to the Creative Commons licence, and indicate if changes were made. The images or other third party material in this article are included in the article's Creative Commons licence, unless indicated otherwise in a credit line to the material. If material is not included in the article's Creative Commons licence and your intended use is not permitted by statutory regulation or exceeds the permitted use, you will need to obtain permission directly from the copyright holder. To view a copy of this licence, visit http://creativecommons.org/licenses/by/4.0/ The Creative Commons Public Domain Dedication waiver (http://creativecommons.org/publicdomain/zero/1.0/) applies to the data made available in this article, unless otherwise stated in a credit line to the data. 


\section{Background}

Periodontal disease (PD) is one of the most common inflammatory disease in dogs, with reports suggesting that 80 to $85 \%$ of dogs with more than 2 years will develop this disease [1-3]. PD is initiated by the formation of a polymicrobial biofilm in the teeth surface (dental plaque), which induces a local inflammatory response, leading to gingivitis and/or several degrees of periodontitis [3].

The formation of dental plaque is a multi-stage process, that begins by the formation of a pellicle in the teeth surface. This pellicle is mainly composed by salivary glycoproteins, that cover the dental surface and allow oral bacteria to adhere and establish the biofilm [3, 4].

Several bacteria are reported to be present at different stages of dental plaque formation. Early or primary colonizers are responsible for the initial formation of the biofilm and include aerobic bacteria, such as Bergeyella, Neisseria, Moraxella, Corynebacterium and Stenotrophomonas species, that interact with the pre-formed pellicle, with other bacteria from the same species (auto-aggregation) and with bacteria from different species (coaggregation) [4-8]. They also participate in the formation of the biofilm matrix, composed by salivary glycoproteins, extracellular polysaccharides, lipids and cellular debris, that hold the biofilm and facilitate the adherence of additional bacteria [3, 4, 9].

Contrary to the human dental plaque, mostly composed by Gram-positive strains, the canine dental plaque microbiome follows an opposite trend, evolving from a majority of Gram-negative aerobic species to Grampositive anaerobic species $[6,7,10]$. In addition to the primary colonizers, one of the most abundant bacterial species in the oral canine microbiome and with an important role in PD development is Phorphyromonas spp. $[6,7,10-14]$. These bacteria are present in the healthy oral cavity but also in animals with gingivitis or periodontitis. [6, 7]. Its ability to survive in the oral cavity, regardless of the PD stage, and capacity to produce several virulence factors renders Porphyromonas sp. one of the keystone pathogens in PD research [4, 8, 14].

After initial dental plaque formation, other anaerobic bacteria adhere to the formed biofilm, replacing some of the early colonizers and contributing to PD progression. As a late colonizer, Peptostreptococcus canis, an anaerobic. Gram-positive strain, is being strongly related to high grade periodontitis in dogs $[8,9,13,15]$. Other important bacteria frequently related to periodontitis in dogs are Treponema denticola, Prevotella intermedia, Tannerella forsythia, Actinomices canis, Bacteroides sp., Campylobacter rectus, Fusobacterium sp., Pseudomonas sp., Staphylococcus sp., Streptococcus sp. and Capnocytophaga sp. [3, 4, 9, 11, 12, 16, 17]. Moreover, some oral bacteria that participate in PD development, such as Enterococcus faecalis, can reach the bloodstream and be associated with PD-related systemic consequences [18].
Considering the high prevalence of canine PD, effective control measures are essential for its prevention and treatment. Bacterial dental plaque control is crucial. Removal of dental plaque and inhibition of its formation can be achieved by a combination of dental hygiene homecare procedures and application of several oral products, use of specific diet and chew toys, and regular professional periodontal procedures [19-21]. Toothbrushing is the most effective method for daily plaque control by mechanically disruption of the dental plaque, being considered the gold standard method for PD control $[19,22]$. As a complementary measure of toothbrushing, chemical plaque control agents are also useful. These compounds disrupt the polymicrobial biofilm, or prevent its formation [23]. Chlorhexidine is the most frequent antiplaque agent used, being applied as a solution to irrigate the oral cavity before dental scaling or surgical procedures, showing good activity against oral pathogens [24]. Recently, it was been proposed that nisin-biogel is a promising compound to inhibit and eradicate enterococcal PD biofilms in dogs [1]. This compound combines the antimicrobial activity of nisin, and the delivery capacity of the plant-derived polysaccharide guar gum (biogel) [1]. Nisin, produced mainly by Lactococcus lactis, is an antimicrobial peptide with antimicrobial activity against Gram-positive bacteria, some Gram-negative, and multidrug resistant bacteria, both in their planktonic and biofilm forms $[1,25,26]$. Its antibacterial ability results from the interaction with the lipid II in the bacterial cytoplasmic membrane, leading to membrane pore formation and inhibition of cell wall synthesis [1]. Besides the demonstrated antimicrobial activity of the nisin-biogel against oral pathogens $[1,26]$, this compound also keeps its activity in the presence of saliva, present no cytotoxicity up to $200 \mu \mathrm{g} / \mathrm{mL}$, and it has rarely been involved in resistance development [26, 27]. To confirm its ability to control the dental plaque, the main goal of this work was to develop an in vitro polymicrobial biofilm, composed by strains associated to the different stages of PD evolution, in order to evaluate nisin-biogel inhibitory activity against the polymicrobial biofilm, by determining the Minimum Biofilm Inhibitory (MBIC) and Eradication Concentrations (MBEC). The polymicrobial biofilm model was established using five strains, namely Neisseria zoodegmatis CCUG 52598T, Corynebacterium canis CCUG 58627T, Enterococcus faecalis clinical isolate, Porphyromonas cangingivalis DSMZ VPB 4874 and Peptostreptococcus canis CCUG 57081.

\section{Results}

\section{Bacterial coaggregation}

Coaggregation ability between isolates from the collection of enterococci from dogs with PD and the early colonizers $N$. zoodegmatis CCUG 52598T and C. canis 
CCUG 58627T was evaluated at 2 and 24 hours. Results are presented in Table 1 . None of the enterococci presented more than $30 \%$ of aggregation ability with both N. zoodegmatis CCUG 52598T and C. canis CCUG 58627T, in both incubation periods. The Enterococcus isolates that presented a coaggregation with N. zoodegmatis CCUG 52598T and C. canis CCUG $58627 \mathrm{~T}$ higher than $30 \%$, at 24 hours of incubation were: M3b, M4c, M15b, M15d, M21c, M25a, M25c, $\mathrm{M} 29 \mathrm{~b}$ and M32a. Considering the increasing aggregation ability over time and the aggregation value, the E. faecalis $\mathrm{M} 32 \mathrm{a}$ isolate was selected to be used in the following experiments.

Then, evaluation of auto-aggregation and coaggregation abilities were performed between all five bacteria selected for the biofilm model: $N$. zoodegmatis CCUG 52598T, C. canis CCUG 58627T, E. faecalis (M32a), P. cangingivalis DSMZ VPB 4874 and $P$. canis CCUG 57081. Results are presented in Table 2. Only $40 \%(4 / 10)$ of the bacterial dual suspensions showed coaggregation higher than $30 \%$ at 2 hours. All bacterial dual suspensions exhibited a percentage of coaggregation higher than $30 \%$ at 24 hours.

\section{Polymicrobial biofilm formation and Fluorescence in situ hybridization (FISH)}

The protocol used allowed to form polymicrobial biofilms, as all five bacterial species were detected by FISH in the $48 \mathrm{~h}$ polymicrobial biofilm (Fig. 1). Species representativity in the biofilm model varied, being $N$. zoodegmatis CCUG 52598T the one present in the lower concentration, followed by C. canis CCUG 58627T and P. canis CCUG 57081. E. faecalis (M32a) and P. cangingivalis DSMZ VPB 4874 were the most abundant species in the biofilm model.

\section{Determination of the nisin-biogel minimum biofilm inhibitory concentration (MBIC) and minimum biofilm eradication concentration (MBEC) regarding the polymicrobial biofilm}

The polymicrobial biofilm was susceptible to nisinbiogel and chlorhexidine solutions. Considering the control chlorhexidine, the mean MBIC value was $0.00094 \%$, and the mean MBEC value was $0.00321 \% \pm 0.002$. The mean MBIC value of nisin-biogel against the polymicrobial biofilm was $26.39 \pm 5.89 \mu \mathrm{g} / \mathrm{mL}$, and the mean MBEC value determined was $62.5 \pm 27.73 \mu \mathrm{g} / \mathrm{mL}$.

Table 1 Coaggregation ability between the enterococci collection, Neisseria zoodegmatis CCUG 52598T and Corynebacterium canis CCUG 58627T

\begin{tabular}{|c|c|c|c|c|}
\hline \multirow[t]{3}{*}{$\begin{array}{l}\text { Isolate } \\
\text { ID }\end{array}$} & \multicolumn{2}{|c|}{ Neisseria zoodegmatis CCUG 52598T } & \multicolumn{2}{|c|}{$\begin{array}{l}\text { Corynebacterium canis } \\
\text { CCUG 58627T }\end{array}$} \\
\hline & \multicolumn{4}{|c|}{ Coaggregation ability (\%) } \\
\hline & $2 \mathrm{~h}$ & $24 \mathrm{~h}$ & $2 \mathrm{~h}$ & $24 \mathrm{~h}$ \\
\hline $\mathrm{M} 2 \mathrm{~b}$ & $30.65 \pm 2.60$ & $55.96 \pm 0.07$ & $7.94 \pm 4.52$ & $1.08 \pm 1.07$ \\
\hline $\mathrm{M} 2 \mathrm{C}$ & $7.04 \pm 2.30$ & $34.61 \pm 3.24$ & $-0.79 \pm 14.77$ & $16.49 \pm 5.21$ \\
\hline M3b & $4.30 \pm 0.85$ & $31.17 \pm 6.36$ & $6.33 \pm 1.12$ & $37.87 \pm 37.76$ \\
\hline M3d & $-0.10 \pm 2.13$ & $16.81 \pm 0.09$ & $13.57 \pm 7.02$ & $18.26 \pm 2.2$ \\
\hline $\mathrm{M} 4 \mathrm{a}$ & $5.85 \pm 0.63$ & $14.67 \pm 6.16$ & $23.98 \pm 5.86$ & $20.19 \pm 5.76$ \\
\hline $\mathrm{M} 4 \mathrm{C}$ & $44.78 \pm 0.57$ & $35.99 \pm 0.50$ & $26.78 \pm 8.20$ & $36.14 \pm 9.55$ \\
\hline M15b & $12.32 \pm 0.77$ & $39.48 \pm 2.94$ & $23.48 \pm 21.03$ & $60.89 \pm 20.89$ \\
\hline M15d & $12.05 \pm 2.86$ & $40.17 \pm 0.34$ & $27.04 \pm 1.59$ & $39.40 \pm 14.12$ \\
\hline M21a & $7.43 \pm 0.17$ & $13.72 \pm 1.00$ & $12.05 \pm 13.56$ & $18.58 \pm 8.20$ \\
\hline M21c & $1.77 \pm 4.48$ & $36.6 \pm 1.67$ & $-14.26 \pm 18.26$ & $40.33 \pm 19.19$ \\
\hline M23a & $8.48 \pm 1.08$ & $34.79 \pm 0.48$ & $20.28 \pm 1.92$ & $24.32 \pm 1.80$ \\
\hline M23c & $5.89 \pm 0.47$ & $40.61 \pm 3.36$ & $24.57 \pm 8.74$ & $22.31 \pm 11.48$ \\
\hline M25a & $9.91 \pm 3.72$ & $42.33 \pm 3.93$ & $9.56 \pm 1.68$ & $38.20 \pm 16.02$ \\
\hline$M 25 \mathrm{C}$ & $4.18 \pm 0.83$ & $36.61 \pm 6.15$ & $-3.66 \pm 7.71$ & $33.04 \pm 21.65$ \\
\hline M29b & $44.76 \pm 0.07$ & $40.53 \pm 1.19$ & $3.96 \pm 17.77$ & $38.85 \pm 8.47$ \\
\hline M32a & $19.62 \pm 0.41$ & $44.84 \pm 4.39$ & $35.57 \pm 7.24$ & $60.02 \pm 10.57$ \\
\hline M32b & $-3.82 \pm 6.99$ & $21.81 \pm 0.41$ & $3,02 \pm 3,00$ & $7.44 \pm 7.21$ \\
\hline
\end{tabular}

Legend: Determination of the coaggregation ability (\%) between the isolates from the enterococci collection obtained from the oral cavity of dogs with PD, and Neisseria zoodegmatis CCUG 52598T and Corynebacterium canis CCUG 58627T, after 2 and 24 hours. ID - identification. \% - percentage (mean \pm standard deviation). $\mathrm{h}$ - hours 
Table 2 Auto-aggregation and coaggregation ability (\%) determination

\begin{tabular}{lcc}
\hline Bacterial species & \multicolumn{2}{c}{ Coaggregation (\%) } \\
\cline { 2 - 3 } & $\mathbf{2} \mathbf{~ h}$ & $\mathbf{2 4} \mathbf{h}$ \\
\hline N. zoodegmatis & $7.07 \pm 1.30$ & $33.27 \pm 1.45$ \\
N. zoodegmatis + E. faecalis & $19.62 \pm 0.41$ & $44.84 \pm 4.39$ \\
N. zoodegmatis + C. canis & $48.99 \pm 15.12$ & $59.12 \pm 6.01$ \\
N. zoodegmatis + P. canis & $18.06 \pm 1.11$ & $48.79 \pm 0.57$ \\
N. zoodegmatis + P. cangingivalis & $16.57 \pm 6.80$ & $46.47 \pm 8.77$ \\
E. faecalis & $6.82 \pm 4.8$ & $28.94 \pm 6.42$ \\
E. faecalis + C. canis & $35.57 \pm 7.24$ & $60.02 \pm 10.57$ \\
E. faecalis + P. canis & $9.00 \pm 6.41$ & $42.33 \pm 1.73$ \\
E. faecalis + P. cangingivalis & $16.77 \pm 6.28$ & $46.24 \pm 17.03$ \\
C. canis & $83.74 \pm 2.8$ & $82.42 \pm 5.16$ \\
C. canis + P. canis & $43.14 \pm 11.91$ & $62.77 \pm 9.23$ \\
C. canis + P. cangingivalis & $46.58 \pm 18.60$ & $60.24 \pm 16.55$ \\
P. canis & $24.48 \pm 16.69$ & $49.37 \pm 6.58$ \\
P. canis + P. cangingivalis & $25.27 \pm 12.75$ & $59.25 \pm 20.25$ \\
P. cangingivalis & $14.31 \pm 5.83$ & $45.09 \pm 1.45$ \\
\hline
\end{tabular}

Legend: Auto-aggregation and coaggregation ability (\%), after 2 and 24 hours, between Neisseria zoodegmatis CCUG 52598T, Corynebacterium canis CCUG 58627T, Enterococcus faecalis (M32a), Porphyromonas cangingivalis DSMZ VPB 4874 and Peptostreptococcus canis CCUG 57081. \% - percentage (mean \pm standard deviation). $\mathrm{h}$ - hours

\section{Discussion}

Oral health is undoubtedly a relevant topic in veterinary medicine. With a prevalence that can be higher than $80 \%$, PD represents one of the most widespread inflammatory disease in dogs $[2,3]$. The study of the canine oral microbiome, as well as new drugs, tools and methodologies to prevent, treat and mimic PD, are of major relevance [1].

The main goal of this work was to develop an in vitro model of a canine dental plaque biofilm to test the antimicrobial ability of a new compound, the nisin-biogel, in conditions that better simulate what is observed in vivo.

First, it was necessary to select a group of bacteria with relevant roles in PD development and progression, and to understand if they were able to co-aggregate. Two early colonizers were chosen, $N$. zoodegmatis CCUG 52598T and C. canis CCUG 58627T, and used to select one isolate from our enterococci collection, obtained from the oral cavity of dogs with PD [7, 28]. From the 17 enterococci tested, nine presented a coaggregation ability higher than $30 \%$ at 24 hours with both primary colonizers (Table 1). Combining an increasing coaggregation ability between 2 and 24 hours and the better coaggregation result at 24 hours, E. faecalis M32a was selected to be included in the biofilm model experiment. Enterococci are usually present in the canine oral cavity, having the capacity of becoming opportunistic

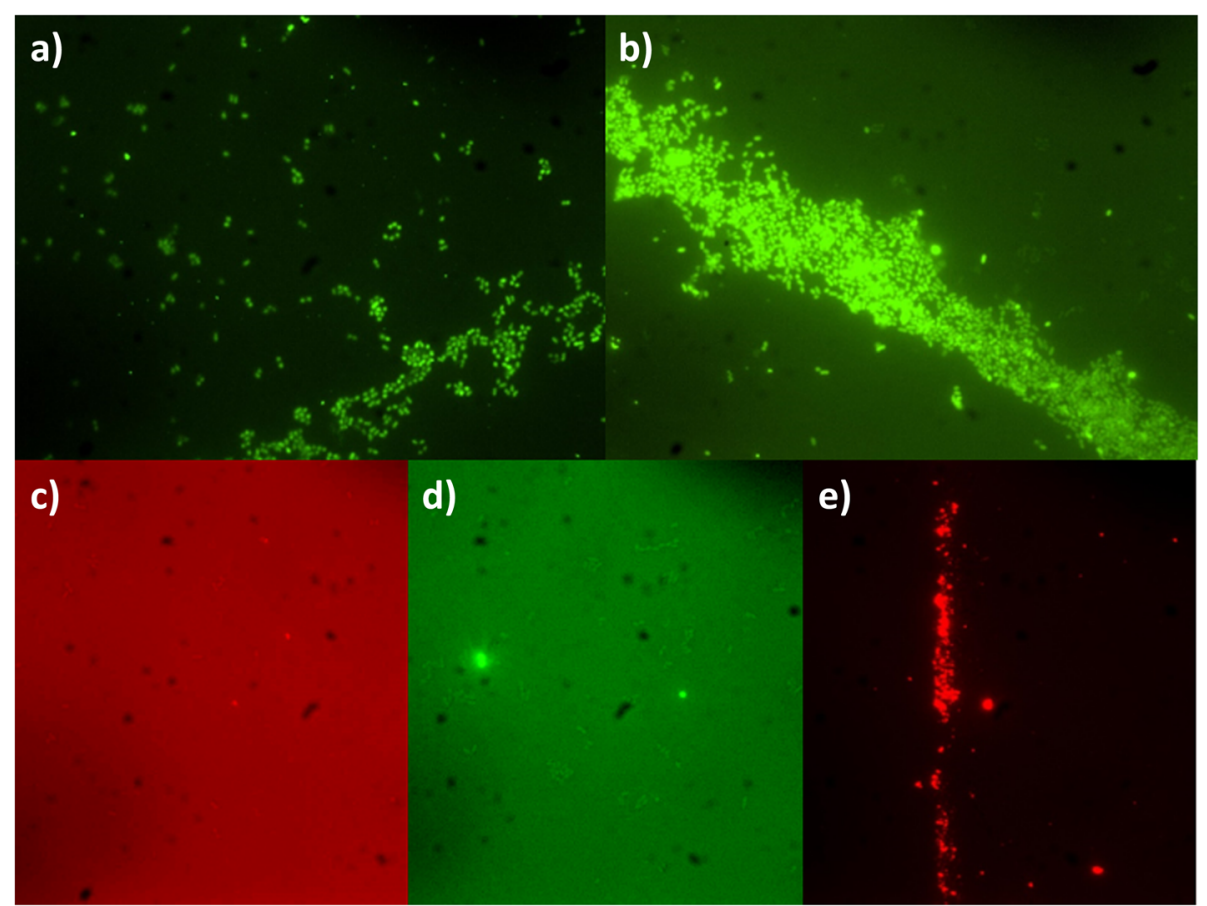

Fig. 1 Bacterial detection through the different specific FISH protocols applied to samples of the polymicrobial biofilm. Legend: a) Enterococcus faecalis (M32a); b) Porphyromonas cangingivalis. DSMZ VPB 4874; c) Neisseria zoodegmatis CCUG 52598T; d) Corynebacterium canis CCUG 58627T. and e) Peptostreptococcus canis CCUG 57081 
pathogens. Being facultative anaerobes, enterococci can persist in a mature biofilm and may facilitate the adherence of other bacteria to the biofilm, also having a possible link to the development of PD-related systemic diseases $[18,28]$.

After that, auto-aggregation and coaggregation ability of the selected enterococci was tested using two other bacterial strains, $P$. cangingivalis DSMZ VPB 4874 and $P$. canis CCUG 57081. $P$. cangingivalis is a highly abundant bacteria in the oral cavity of healthy dogs and in animals with inflamed periodontal tissues $[6,10,13,14]$, since its metabolic flexibility supports its survival in both environments [4, 13]. On another hand, $P$. canis is a late colonizer frequently identified in severe PD cases $[9,15]$.

The five species tested showed a coaggregation capacity higher than $30 \%$ after 24 hours. Usually, coaggregation interactions are highly specific and involve recognition of receptors between bacteria, with involvement of adhesins and protein-saccharide interactions due to the presence of flagella and pili $[8,29,30]$. Coaggregation can also actively modulate gene expression, being one important factor on biofilm formation [29]. In our study, it was possible to observe that, after only 2 hours of incubation, the two early colonizers ( $N$. zoodegmatis CCUG 52598T and C. canis CCUG 58627T) showed the higher coaggregation capacity, followed by the dual suspension of $C$ canis CCUG $58627 \mathrm{~T}$ and $P$. cangingivalis DSMZ VPB 4874. Then, after 24 hours of incubation, $C$. canis CCUG 58627T also presented a high coaggregation ability, with $P$. canis CCUG 57081, $P$. cangingivalis DSMZ VPB 4874 and N. zoodegmatis CCUG 52598T. Similarly to our study, Elliot et al. (2006) [5] and Holcombe at al. (2014) [7] also showed that Corynebacterium sp. can co-aggregate with several oral bacteria, being an important pioneer in oral biofilms. As described, $P$. cangingivalis has an important role in PD development $[4,8]$, resulting from its high coaggregation ability with both early and late colonizers, at 2 and 24 hours, as showed in this work. In fact, coaggregation evaluation is a very important step to predict the behaviour of bacteria in a biofilm community.

Considering dental plaque establishment, and to simulate the salivary pellicle present at the teeth surface, the pegs used to form the polymicrobial biofilms, were incubated 2 hours in CAS. This canine artificial saliva was prepared as described by Sanguersrmi et al. (2017) [8], with several components that aim to simulate the biochemical composition of canine saliva. Then, the in vitro oral biofilm model was established using a combination of five strains, as previously described. Considering the low oxygen tension in the subgingival pocket, biofilms were established using a microaerophilic atmosphere to simulate the dental plaque environment and facilitate the adherence of all strains, which present distinct respiratory requirements $[31,32]$.

Polymicrobial biofilm evaluation was performed by Fluorescence In Situ Hybridization (FISH). This technique is an easy to perform and quick method, allowing the identification of microbial populations in a complex community setting [33, 34]. FISH is based on specific hybridization of labelled oligonucleotide probes, with complementary rRNA target sequences present within a permeabilized and morphologically intact bacterial cell [33]. Specific probes for each of the five species present in the biofilm model were selected targeting the bacterial $16 \mathrm{~S}$ rRNA [33]. All five species were identified at the biofilm model after FISH evaluation. However, some differences in bacterial representativity were observed in this study. In fact, some reports describe that early colonizers are essential in the initial biofilm establishment, but with the PD progression, they suffer a reduction, being replaced by secondary or late colonizers, which is in accordance with our results $[11,13]$. This in vitro polymicrobial biofilm is a very interesting model for testing new drugs, and the methodology applied in this study can also be used to develop distinct polymicrobial models.

Considering the high prevalence of PD in dogs, control measures are essential to reduce its impact on animal health. PD prevention can be achieved by home oral hygiene procedures and regular professional periodontal evaluation, with the establishment of therapeutic protocols focusing on the prevention and removal of dental plaque $[19,20,35]$. PD treatment includes non-surgical techniques, aiming at the removal of factors that promote disease progression, and surgical procedures that promote periodontium regeneration [26]. In both cases antimicrobial therapy may be necessary depending on case severity $[19,21,35]$. In order to reduce antimicrobial use, a nisin-biogel was recently proposed as a promising compound to be used in canine PD control [1, 27]. The authors showed that the nisin-biogel can inhibit and eradicate canine enterococcal-dental plaque biofilms [1]. In this work, the nisin-biogel was able to inhibit and eradicate oral polymicrobial biofilms at concentrations two-fold higher than the MBIC values and 3 folds higher than the MBEC values, previously determined for monospecies biofilms [1]. Likewise, other reports also describe nisin as having an in vitro antimicrobial activity against several dental plaque bacteria, reinforcing its potential for PD control $[25,26]$. The potential cytotoxicity of nisin and nisin-biogel has already evaluated regarding several eukaryotic cells, revealing no toxicity up to $200 \mu \mathrm{g} / \mathrm{mL}[26,27]$, and the European Food Safety Authority have defined an ADI of $1 \mathrm{mg} / \mathrm{Kg} /$ day for nisin use as a food additive [36]. All these points support the safety of nisin in a potential dental topical application in vivo. 
In addition, our study showed that the polymicrobial biofilm was inhibited and eradicated by chlorhexidine, at concentrations lower than $0.12 \%$, which is the currently concentration recommended to be used in Veterinary odontology [24]. Chlorhexidine is an antiseptic used in solution to irrigate the oral cavity before dental scaling or surgical procedures, showing good activity against oral pathogens [24]. Some products containing chlorhexidine are available to use in PD control [37]. However, it is described that chlorhexidine presents negative effects when used as a prolonged therapy, such as taste loss, pigmentation of the enamel or lesions of the oral mucosa [37]. In addition, oral bacteria may be resistant to chlorhexidine or present a cross resistance profile to chlorhexidine and several antimicrobials [38]. chlorhexidine should not be applied for long periods, not being recommended for PD prevention [37]. Considering that it is of major importance to develop new products, such as the nisin-biogel, to be used as a regular approach for PD control, aiming at reducing antimicrobial therapy.

In conclusion, the in vitro model of a periodontal polymicrobial biofilm developed, aiming at mimicking the in vivo conditions present in dogs oral cavity, allowed to observe that the nisin-biogel developed by our research team can be effective against multi-species biofilms, reinforcing its potential for controlling a relevant disease of these animals.

\section{Conclusions}

Periodontal disease is one of the most common inflammatory disease in dogs, being caused by a polymicrobial biofilm formed in the teeth surface. Early colonizers, such as N. zoodegmatis and C. canis, adhere to the salivary pellicle in the teeth surface and allow the aggregation of secondary and late colonizers, to form a mature biofilm. In this work it was possible to develop an in vitro model of a periodontal polymicrobial biofilm, composed by five bacterial strains frequently present in dog's dental plaque. In addition, this model was used to evaluate the inhibitory activity of a nisin-biogel, developed by our research team, allowing to observe that the biogel can inhibit and eradicate multi-species biofilms, reinforcing its potential to be used in the control of dogs PD.

\section{Methods}

\section{Bacterial collection and culture conditions}

Bacterial reference strains Neisseria zoodegmatis CCUG $52598 \mathrm{~T}$ (from a human wound caused by a dog bite), Corynebacterium canis CCUG 58627T (from a human wound caused by a dog bite), Peptostreptococcus canis CCUG 57081 (from a canine dental plaque) and Porphyromonas cangingivalis DSMZ VPB 4874 (from a canine periodontal pocket) were used in this study. Each strain was selected due to their association to different stages of PD progression.

A collection of 17 biofilm-producer enterococci, obtained from the oral cavity of dogs diagnosed with PD was also used to select one isolate to be included in the formation of the five-species polymicrobial biofilm model [28].

N. zoodegmatis CCUG 52598T, C. canis CCUG $58627 \mathrm{~T}$ and the enterococci were routinely grown on Brain Heart Infusion (BHI) agar plates (VWR, Belgium) under aerobic conditions for 24 hours at $37^{\circ} \mathrm{C}$. P. canis CCUG 57081 was grown on Chocolate Agar plates (VWR, Belgium) under anaerobic conditions for 48 hours at $37^{\circ} \mathrm{C}$. P. cangingivalis DSMZ VPB 4874 was grown on Columbia Blood agar plates (VWR, Belgium) under anaerobic conditions for 48 hours at $37^{\circ} \mathrm{C}$. All bacteria were also grown on Brucella Broth medium (Liofilchem, Italy), supplemented with hemin $(5 \mu \mathrm{g} / \mathrm{mL})$ (Sigma-Aldrich, USA) and vitamin $\mathrm{K}_{1}(1 \mu \mathrm{g} / \mathrm{mL})$ (Liofilchem, Italy) [39].

\section{Nisin- biogel solutions}

A nisin stock solution $(1000 \mu \mathrm{g} / \mathrm{mL}, 40000 \mathrm{IU} / \mathrm{mL})$ (2.5\% purity Sigma-Aldrich, USA) and a $1.5 \%$ guar-gum biogel (w/v) (Sigma-Aldrich, USA) solution were prepared as described elsewhere [1].

Nisin stock solution was diluted in sterile distilled water to achieve the following concentrations: 750,625 , $500,375,250,125,50,25$ and $12.5 \mu \mathrm{g} / \mathrm{mL}$. Then these solutions were incorporated within the guar-gum gel in a proportion of $1: 1$, to obtain a $0.75 \%$ gel $(\mathrm{w} / \mathrm{v})$. Working solutions were kept at $4^{\circ} \mathrm{C}$ during the study.

\section{Chlorhexidine solutions}

A stock solution of chlorhexidine gluconate at $4 \%(\mathrm{w} / \mathrm{v})$ (AGA, Portugal) was diluted in sterile distilled water and used as a control, as it is described as the drug of choice for PD control [24, 37]. Two-fold dilutions from 0.24$0.00047 \%$ were tested, according to the concentrations used in canine odontology [24,37].

\section{Canine artificial saliva}

Preparation of canine artificial saliva (CAS) was performed as described by Sanguansermsri et al. (2018) [8]. CAS was composed (per liter) by $1 \mathrm{~g}$ Lab Lemco Powder (Thermo Fisher Scientific, Denmark), 2 g yeast extract (Sigma-Aldrich, USA), $5 \mathrm{~g}$ proteose peptone (Merk, Germany), $2.5 \mathrm{~g}$ hog gastric mucin (Sigma-Aldrich, USA), $2.34 \mathrm{~g} \mathrm{NaCl}, 1.5 \mathrm{~g} \mathrm{KCl}, 0.1 \mathrm{~g} \mathrm{CaCl}_{2}$ and $1.25 \mathrm{~mL}$ of $40 \%$ urea. The solution was sterilized by autoclave, except for urea that was filtered using a $0.22 \mu \mathrm{m}$ cellulose acetate membrane filter and then added to the remaining components. 


\section{Bacterial coaggregation}

Coaggregation between bacterial strains was evaluated as described by Datta et al. (2017) [30] and Sanguansermsri et al. (2018) [8], with some modifications. Aerobic bacteria ( $N$. zoodegmatis CCUG 52598T, C. canis and enterococci CCUG 58627T) were grown in $5 \mathrm{~mL}$ BHI broth at $37^{\circ} \mathrm{C}$ for 24 hours, and anaerobic bacteria $(P$. cangingivalis DSMZ VPB 4874 and $P$. canis CCUG 57081) in $5 \mathrm{~mL}$ of supplemented Brucella Broth under anaerobic conditions for 48 hours at $37^{\circ} \mathrm{C}$. Then cells were harvested by centrifugation at $5000 \mathrm{~g}$ for 7 minutes at $4{ }^{\circ} \mathrm{C}$ and suspended in coaggregation buffer $(1 \mathrm{mmol}$ $\mathrm{L}^{-1}$ Tris- $\mathrm{HCl} \mathrm{pH} 8,150 \mathrm{mmol} \mathrm{L}^{-1} \mathrm{NaCl}, 0.1 \mathrm{mmol} \mathrm{L}^{-1}$ $\mathrm{CaCl}_{2} \cdot 2 \mathrm{H}_{2} \mathrm{O}, 0.1 \mathrm{mmol} \mathrm{L}{ }^{-1} \mathrm{MgCl}_{2}$ and $0.02 \% \mathrm{NaN}_{3}$ ). The optical density at $600 \mathrm{~nm}$ (OD600) of each suspension was adjusted to 1 .

Equal volumes of each bacterial suspension $(1 \mathrm{~mL})$ were mixed and vortexed for 30 seconds, after which the OD600 was measured (OD1). Then, the dual suspension was centrifuged for 2 minutes at $650 \mathrm{~g}$ and incubated at room temperature for 2 hours, afterwhich the OD600 of $0.2 \mathrm{~mL}$ of the upper layer was measured (OD2). This procedure was repeated after 24 hours (OD24). The percentage coaggregation was assessed using the following formula:

$$
\% \text { Coaggregation }=\frac{\mathrm{OD} 1-\mathrm{OD} 2(\text { or OD24 })}{\mathrm{OD} 1} \times 100
$$

A percentage higher than $30 \%$ was considered as a coaggregation indicator [30].

Coaggregation between enterococci isolates $(n=17)$ and $N$. zoodegmatis CCUG 52598T and C. canis CCUG $58627 \mathrm{~T}$, was determined to select the enterococci with the higher coaggregation ability to be used in the further protocols. Afterwards, coaggregation of the selected isolates with the anaerobic strains was determined, as well as auto-aggregation between the five bacterial species.

The experiments were repeated three times in independent days.

\section{Polymicrobial biofilm formation}

A polymicrobial biofilm composed by five bacterial species, including $N$. zoodegmatis CCUG 52598T, C. canis CCUG 58627T, E. faecalis clinical isolate, $P$. cangingivalis DSMZ VPB 4874 and $P$. canis CCUG 57081, was performed, based on the protocol described by Vandeplassche et al. (2017) [32] and Sanguansermsri et al. (2018) [8] with some modifications. To achieve that, a modified version of the Calgary Biofilm Pin Lid Device and a microaerophilic environment (Merk, Germany) were used. Briefly, 40 $\mu \mathrm{L}$ of a $10^{7} \mathrm{CFU} / \mathrm{mL}$ bacterial suspension, from each strain, in supplemented Brucella broth medium were deposited in the wells of a 96-well microplate (Nunc ${ }^{\mathrm{ma}}$,
Thermo Scientific). Then, a peg lid (Nunc ${ }^{\text {Tw }}$ Immuno TSP Lids, Thermo Scientific $\left.{ }^{\mathrm{Tm}}\right)$, previously incubated for 2 hours in CAS, was applied in the microplate. After a $48 \mathrm{~h}$ incubation at $37{ }^{\circ} \mathrm{C}$, in microaerophilic conditions, pegs were washed three times in $0.9 \%$ $\mathrm{NaCl}$, transferred to a new microplate filled with fresh Brucella broth, sealed and incubated in an ultrasonic bath (Gramt, Ultrasonic Bath, MXB14) for $15 \mathrm{~min}$ at high frequency $(50-60 \mathrm{~Hz})$ [1]. Afterwards, the peg lid was replaced by a conventional one, and the microplate was incubated at $37{ }^{\circ} \mathrm{C}$, for 48 hours, in microaerophilic conditions. Finally, bacterial suspensions from each well were evaluated by Fluorescence In Situ Hybridization (FISH) to confirm the presence of the five bacterial strains in the polymicrobial biofilm.

\section{Fluorescence In Situ Hybridization (FISH)}

The FISH protocol was performed as described by Oliveira et al. (2006) [40] with some modifications. Teflon slides (Heinz Herenz, Hamburg, Germany) were used as hybridization supports. Before hybridization, slides were washed in ethanol, incubated in a 2\% 3-trimethoxysilylpropilamine solution (Merck, Germany) in acetone (PanReac AppliChem, USA) for $1 \mathrm{~min}$, twice in acetone for $1 \mathrm{~min}$ and washed in distilled water [40].

Then, $10 \mu \mathrm{l}$ of the bacterial suspensions originated from the polymicrobial biofilms were placed in the wells of the slide. After air-drying, suspensions were fixed with a $4 \%$ paraformaldehyde (w/v) solution in PBS for 4 hours at room temperature. After fixation, suspensions were dehydrated with ethanol at 50, 80 and 96\%, during $3 \mathrm{~min}$ at each concentration, permeabilized with lysozyme $(0.5 \mu \mathrm{g} / \mathrm{mL})$ (Sigma-Aldrich, USA) during $20 \mathrm{~min}$ at room temperature, and dehydrated again. Afterwards, $10 \mu \mathrm{l}$ of hybridization buffer $(0.9 \mathrm{M} \mathrm{NaCl}, 20 \mathrm{mMTris}-$ $\mathrm{HCl}, \mathrm{pH} 7.2,0.01 \%$ SDS) were added, containing $5 \mathrm{ng} /$ $\mathrm{ml}$ of each specific probe (STABVIDA, Portugal) mentioned in Table 3. Slides were incubated in a humid chamber (Omnislide Thermal Cycling Block, Hybaid Omnislide System, Thermoelectron Corporation, USA) during $3 \mathrm{~h}$, at $46^{\circ} \mathrm{C}$ for $N$. zoodegmatis CCUG 52598T, $E$. faecalis and $P$. cangingivalis DSMZ VPB 4874 detection, at $48^{\circ} \mathrm{C}$ for $C$. canis CCUG58627T detection, and at $35{ }^{\circ} \mathrm{C}$ for $P$. canis CCUG 57081 detection. Then, slides were washed in a buffer solution $(0.9 \mathrm{M} \mathrm{NaCl}$, $20 \mathrm{mM}$ Tris- $\mathrm{HCl}, \mathrm{pH} 7.2,0.1 \%$ SDS) at the same temperatures during $15 \mathrm{~min}$, mounted in Vectashield Mounting Medium (Vector Laboratories, USA) and visualized by fluorescent microscopy at 1000X (objective HCX PLAN APD) in a Leica DMR microscope (Leica Microsystems Lda., Lisbon, Portugal), equipped with a mercury lamp of $100 \mathrm{~W}$, an I3 filter for excitation 
Table 3 Specific fluorescent probes used in the FISH protocol

\begin{tabular}{llll}
\hline Bacteria & Probe sequence & Fluorochrome & Reference \\
\hline Neisseria sp. & 5'-CGGGTGAGTAACATATCGG-3' & Rhodamine & [41] \\
$\begin{array}{llll}\text { E. } \\
\text { faecalis }\end{array}$ & Fluorescein & [42] \\
$\begin{array}{l}\text { Corynebacterium } \\
\text { sp. }\end{array}$ & 5'-CCGGATCCCCTCTGATGGG-3' & Fluorescein & [43] \\
$\begin{array}{l}\text { Porphyromonas } \\
\text { sp. }\end{array}$ & 5'-TGTCAGTCGCAGTATGGCAA-3' $^{\prime}$ & Fluorescein & [44] \\
Peptostreptococcus sp. & 5'-TGCGCAAGCATGAAA-3' & Rhodamine & [45] \\
\hline
\end{tabular}

between 450 and $490 \mathrm{~nm}$ and a N2.1 filter for excitation between 515 and $560 \mathrm{~nm}$.

\section{Determination of the nisin-biogel minimum biofilm inhibitory concentration (MBIC) and minimum biofilm eradication concentration (MBEC)}

A $48 \mathrm{~h}$ polymicrobial biofilm composed by five bacterial species was established as previously described, and its susceptibility to the nisin-biogel was determined using a modified version of the Calgary Biofilm Pin Lid Device. Gluconate chlorhexidine was used as control, based on its current use in PD control [24, 37]. MBIC and MBEC determinations were performed as described by Cunha et al. (2018) [1] with some modifications. After polymicrobial biofilm formation, pegs were washed three times with $0.9 \% \mathrm{NaCl}$ and transferred to new 96-well plates containing $160 \mu \mathrm{L}$ of Brucella broth and $40 \mu \mathrm{L}$ of the nisin-biogel or chlorhexidine concentrations for MBIC determination. For that, the new plate was incubated for $24 \mathrm{~h}$ at $37{ }^{\circ} \mathrm{C}$ in microaerophilic conditions, after which the $\mathrm{MBIC}$ value was determined by direct observation as the lowest concentration of nisin that inhibit bacterial growth. Then, for MBEC determination pegs were washed again three times and transferred to a 96-well plate containing $200 \mu \mathrm{L}$ of fresh Brucella broth medium. These plates were sealed and incubated in an ultrasonic bath, for $15 \mathrm{~min}$ at high frequency (50$60 \mathrm{~Hz}$ ). Afterwards, the peg lid was replaced by a conventional one, and the plate was incubated at $37{ }^{\circ} \mathrm{C}$ for $48 \mathrm{~h}$ in microaerophilic conditions. After incubation, MBEC value was determined visually as the lowest concentration of nisin or chlorhexidine that eliminate microbial growth [46]. MBIC and MBEC values were confirmed by optical density measurement at $600 \mathrm{~nm}$, using a microtiter plate reader (BMG Labtech, FLUOstar OPTIMA) [1].

A positive control (bacterial suspension) and a negative control (medium) were included. At the end of the experiment, the presence of the five bacterial strains in the positive controls was confirmed by FISH.
Experiments were conducted in triplicate, in independent days.

\section{Statistical analysis}

Data statistical analysis was carried out using Microsoft Excel $2016^{\circ}$. Quantitative variables are expressed as mean values \pm standard deviation.

\section{Abbreviations}

BHI: Brain Heart Infusion; CAS: Canine Artificial Saliva; FISH: Fluorescence In Situ Hybridization; ID: Identification; MBIC: Minimum Biofilm Inhibitory Concentration; MBEC: Minimum Biofilm Eradication Concentration; OD: Optical Density; PD: Periodontal Disease

\section{Acknowledgements}

Authors would like to acknowledge to CIISA - Centro de Investigação Interdisciplinar em Sanidade Animal, Faculdade de Medicina Veterinária, Universidade de Lisboa, Lisboa, Portugal, Project UIDB/00276/2020 (funded by FCT), and to the Foundation for Science and Technology (Eva Cunha PhD fellowship SFRH/BD/131384/2017).

\section{Authors' contributions}

EC performed the experiments, analysed the data and wrote the manuscript. SR helped to perform the experiments. CC helped to perform the experiments and to draft the manuscript. LT contributed to the analysis and interpretation of data. LMC helped to analyse the data and to draft and revise the manuscript. $\mathrm{MO}$ conceived the study and participated in its coordination, helped to draft the manuscript and supervision throughout. All authors read and approved the final manuscript.

\section{Funding}

This work was supported by CIISA - Centro de Investigação Interdisciplinar em Sanidade Animal, Faculdade de Medicina Veterinária, Universidade de Lisboa, Lisboa, Portugal, Project UIDB/00276/2020 (funded by FCT), and by the Foundation for Science and Technology (Eva Cunha PhD fellowship SFRH/BD/131384/2017).

The funding sources were not involved in the conduct of the research and in the preparation of the article.

\section{Availability of data and materials}

The datasets used and/or analysed during the current study are available from the corresponding author on reasonable request.

Ethics approval and consent to participate Not applicable.

Consent for publication Not applicable.

Competing interests

The authors declare that they have no competing interests. 
Received: 4 August 2020 Accepted: 26 October 2020 Published online: 02 December 2020

\section{References}

1. Cunha E, Trovão T, Pinheiro A, Nunes T, Santos R, Moreira Da Silva J, São Braz B, Tavares L, Veiga AS, Oliveira M. Potential of two delivery systems for nisin topical application to dental plaque biofilms in dogs. BMC Vet Res. 2018;14(1):1-10. https://doi.org/10.1186/s12917-018-1692-9.

2. Stella JL, Bauer AE, Croney CC. A cross-sectional study to estimate prevalence of periodontal disease in a population of dogs (Canis familiaris) in commercial breeding facilities in Indiana and Illinois. PLOS ONE. 2018; 13(1):e0191395. https://doi.org/10.1371/journal.pone.0191395.

3. Stepaniuk K. Periodontology. In: Lobprise HB, Dodd JR, editors. Wiggs's Veterinary Dentistry. Hoboken: John Wiley \& Sons inc; 2019. pp. 81-108.

4. Kačírová J, Mad’ar M, Štrkolcová G, Mad’ari A, Nemcová R. Dental biofilm as etiological agent of canine periodontal disease. IntechOpen. 2019. https:// doi.org/10.5772/intechopen.88305.

5. Elliott DR, Wilson M, Buckley CMF, Spratt DA. Aggregative behavior of bacteria isolated from canine dental plaque. Appl Environl Microbiol. 2006; 72(8):5211-7. https://doi.org/10.1128/AEM.01060-05.

6. Davis IJ, Wallis C, Deusch O, Colyer A, Milella L, Loman N, Harris S. A crosssectional survey of bacterial species in plaque from client owned dogs with healthy gingiva, gingivitis or mild periodontitis. PLoS One. 2013;8(12): e83158. https://doi.org/10.1371/journal.pone.0083158.

7. Holcombe LJ, Patel N, Colyer A, Deusch O, O'Flynn C, Harris S. Early canine plaque biofilms: characterization of key bacterial interactions involved in initial colonization of enamel. PLoS One. 2014;9(12):e113744. https://doi.org/ 10.1371/journal.pone.0113744.

8. Sanguansermsri P, Nobbs AH, Jenkinson HF, Surarit R. Interspecies dynamics among bacteria associated with canine periodontal disease. Mol Oral Microbiol. 2018:33(1):59-67. https://doi.org/10.1111/omi.12199.

9. Polkowska I, Sobczyńska-rak A, Golyńska M. Analysis of gingival pocket microflora and biochemical blood parameters in dogs suffering from periodontal disease. In Vivo. 2014;28(6):1085-90.

10. Dewhirst FE, Klein EA, Thompson EC, Blanton JM, Chen T, Milella L, Buckley CMF, Davis IJ, Bennett ML, Marshall-Jones ZV. The canine oral microbiome. PLoS One. 2012;7(4):e36067. https://doi.org/10.1371/journal.pone.0036067.

11. Riggio MP, Lennon A, Taylor DJ, Bennett D. Molecular identification of bacteria associated with canine periodontal disease. Vet Microbiol. 2011;150: 394-400. https://doi.org/10.1016/j.vetmic.2011.03.001.

12. Di Bello A, Buonavoglia A, Franchini D, Valastro C, Ventrella G, Greco MF, Corrent M. Periodontal disease associated with red complex bacteria in dogs. J Small Anim Pract. 2014;55:160-3. https://doi.org/10.1111/jsap.12179.

13. Wallis C, Marshall M, Colyer A, O'Flynn C, Deusch O, Harris S. A longitudinal assessment of changes in bacterial community composition associated with the development of periodontal disease in dogs. Vet Microbiol. 2015;181(34):271-82. https://doi.org/10.1016/j.vetmic.2015.09.003.

14. Silva AN, Avila ED, Nakano V, Avila-Campos MJ. Pathogenicity and genetic profile of oral Porphyromonas species from canine periodontitis. Arch Oral Biol. 2017;83:20-4. https://doi.org/10.1016/j.archoralbio.2017.07.001.

15. Lawson PA, Johnson CN, Bengtsson L, Charalampakis G, Dahlén G, Moore E, Falsen E. Anaerobe Peptostreptococcus canis sp. nov., isolated from subgingival plaque from canine oral cavity. Anaerobe. 2012;18(6):597-601. https://doi.org/10.1016/j.anaerobe.2012.10.008.

16. Nises J, Rosander A, Pettersson A, Backhans A. The occurrence of Treponema spp. in gingival plaque from dogs with varying degree of periodontal disease. PLoS ONE. 2018;13(8):e0201888. https://doi.org/10.1371/journal. pone. 0201888

17. Gadê-Neto CR, Rodrigues RR, Louzada LM, Arruda-Vasconcelos R, Teixeira FB, Casarin RCV, Gomes BPFA. Microbiota of periodontal pockets and root canals in induced experimental periodontal disease in dogs. J Investig Clin Dent. 2019;10(4):e12439. https://doi.org/10.1111/jicd.12439.

18. Semedo-Lemsaddek T, Tavares M, São Braz B, Tavares L, Oliveira M. Enterococcal infective endocarditis following periodontal disease in dogs. PLoS One. 2016;11(1):e0146860. https://doi.org/10.1371/journal. pone.0146860.

19. Harvey CE. Management of periodontal disease: understanding the options. Vet Clin North Am Small Anim Pract. 2005;35(4):819-36. https://doi.org/10. 1016/j.cvsm.2005.03.002.

20. Roudebush P, Logan E, Hale FA. Evidence-based veterinary dentistry: a systematic review of homecare for prevention of periodontal disease in dogs and cats. J Vet Dent. 2005;22(1):6-15. https://doi.org/10.1177/ 089875640502200101.

21. Albuquerque C, Morinha F, Requicha J, Martins T, Dias I, Guedes-Pinto $H$, Bastos E, Viegas C. Canine periodontitis: the dog as an important model for periodontal studies. Vet J. 2012;191:299-305. https://doi.org/ 10.1016/j.tvjl.2011.08.017.

22. Enlund KB, Brunius C, Hanson J, Hagman R, Höglund OV, Gustas P, Pettersson A. Dental home care in dogs - a questionnaire study among Swedish dog owners, veterinarians and veterinary nurses. BMC Vet Res. 2020; 16,90. https://doi.org/10.1186/s12917-020-02281-y.

23. Jafer M, Patil S, Hosmani J, Bhandi SH, Chalisserry EP, Anil S. Chemical Plaque Control Strategies in the Prevention of Biofilm-associated Oral Diseases. J Contemp Dent Pract. 2016;17(4):337-43. https://doi.org/10.5005/ jp-journals-10024-1851.

24. Bellows J, Berg ML, Dennis S, Harvey R, Lobprise HB, Snyder CJ, Stone AES, Van de Wetering AG. 2019 AAHA Dental care guidelines for dogs and cats. J Am Anim Hosp Assoc. 2019;55(2):49-69. https://doi.org/10. 5326/JAAHA-MS-6933

25. Tong Z, Dong L, Zhou L, Tao R, Ni L. Nisin inhibits dental caries-associated microorganism in vitro. Peptides. 2010;31(11):2003-8. https://doi.org/10. 1016/j.peptides.2010.07.016.

26. Shin JM, Ateia I, Paulus JR, Liu H, Fenno JC, Rickard AH, Kapila YL. Antimicrobial nisin acts against saliva derived multi-species biofilms without cytotoxicity to human oral cells. Front Microbiol. 2015;6:617. https://doi.org/ 10.3389/fmicb.2015.00617.

27. Cunha E, Freitas FB, São Braz B, Moreira Da Silva J, Tavares L, Veiga AS, Oliveira M. Polyphasic validation of a nisin-biogel to control canine periodontal disease. Antibiotics. 2020;9(4):180. https://doi.org/10.3390/ antibiotics9040180.

28. Oliveira M, Tavares M, Gomes D, Touret T, São Braz B, Tavares L, SemedoLemsaddek $T$. Virulence traits and antibiotic resistance among enterococci isolated from dogs with periodontal disease. Comp Immunol Microbiol Infect Dis. 2016;46:27-31. https://doi.org/10.1016/j.cimid.2016.04.002.

29. Jakubovics NS. Intermicrobial interactions as a driver for community composition and stratification of oral biofilms. J Mol Biol. 2015;427(23):366275. https://doi.org/10.1016/j.jmb.2015.09.022.

30. Datta A, Stapleton F, Willcox MDP. Bacterial coaggregation among the most commonly isolated bacteria from contact lens cases. Investig Opthalmology Vis Sci. 2017:58(1):50. https://doi.org/10.1167/iovs.16-20593.

31. Mettraux GR, Gusberti FA, Graf H. Oxygen tension $\left(\mathrm{pO}_{2}\right)$ in untreated human periodontal pockets. J Periodontol. 1984;55(9):516-21.

32. Vandeplassche $E$, Coenye T, Crabbé A. Developing selective media for quantification of multispecies biofilms following antibiotic treatment. PLoS One. 2017;12(11):e0187540. https://doi.org/10.1371/journal.pone.0187540.

33. Schweickert B, Moter A, Lefmann M, Gobel UB. Let them fly or light them up: matrix-assisted laser desorption/ionization time of flight (MALDI-TOF) mass spectrometry and fluorescence in situ hybridization (FISH). APMIS. 2004; 112:856-885. https://doi.org/10.1111/j.1600-0463. 2004.apm11211-1210.x.

34. Amann R, Fuchs BM. Single-cell identification in microbial communities by improved fluorescence in situ hybridization techniques. Nat Rev Microbiol. 2008;6(5):339-48. https://doi.org/10.1038/nrmicro1888.

35. Niemiec BA. Periodontal treatment. Top Companion Anim Med. 2008;23(2): 81-90. https://doi.org/10.1053/j.tcam.2008.02.004.

36. EFSA Panel on Food Additives and Nutrient Sources added to Food (ANS), Younes M, Aggett P, Aguilar F, Crebelli R, Dusemund B, Filipič M, Frutos MJ, Galtier P, Gundert-Remy U, Kuhnle GG, Lambre C, Leblanc J-C, Lillegaard IT, Moldeus P, Mortensen A, Oskarsson A, Stankovic I, Waalkens-Berendsen I, Woutersen RA, Wright M, Herman L, Tobback P, Pizzo F, Smeraldi C, Tard A, Papaioannou A, Gott D. Safety of nisin (E 234) as a food additive in the light of new toxicological data and the proposed extension of use. EFSA Journal. 2017;15(12):1-16. https://doi.org/10.2903/j.efsa.2017.5063.

37. Pieri FA, Daibert AP, Bourguignon E, Moreira MAS. Periodontal disease in dogs. In: Perez-Marin CC, editor. A Bird's-Eye View of Veterinary Medicine. Zagreb: InTech; 2012. pp. 129-32.

38. Cieplik F, Jakubovics NS, Buchalla W, Maisch T, Hellwig E, Al-Ahmad A. Resistance toward chlorhexidine in oral bacteria - is there cause for concern? Front Microbiol. 2019;10:587. https://doi.org/10.3389/fmicb.2019.00587.

39. Clinical and Laboratory Standards Institute (CLSI). Methods for antimicrobial susceptibility testing of anaerobic bacteria; approved standard-Sixth Edition. NCCLS document M11-A6. Wayne: NCCLS; 2004. 
40. Oliveira M, Bexiga R, Nunes SF, Carneiro C, Cavaco LM, Bernardo F, Vilela CL. Biofilm forming ability profiling of Staphylococcus aureus and Staphylococcus epidermidis mastitis isolates. Vet Microbiol. 2006;118(1-2):133-40. https://doi. org/10.1016/j.vetmic.2006.07.008.

41. Walcher M, Skvoretz R, Montgomery-Fullerton M, Jonas V, Brentano S. Description of an unusual Neisseria meningitidis isolate containing and expressing Neisseria gonorrhoeae-specific $16 \mathrm{~S}$ rRNA gene sequences. J Clin Microbiol. 2013;51(10):3199-206. https://doi.org/10.1128/JCM.00309-13.

42. Costa PM, Oliveira M, Bica A, Vaz-Pires P, Bernardo F. Antimicrobial resistance in Enterococcus spp. and Escherichia coli isolated from poultry feed and feed ingredients. Vet Microbiol. 2007; 120(1-2):122-131. https:// doi.org/10.1016/j.vetmic.2006.10.005.

43. Mark WJL, Rossetti BJ, Rieken CW, Dewhirst FE, Borisy GG. Biogeography of a human oral microbiome at the micron scale. Proc Natl Acad Sci. 2016; 113(6):E791-800. https://doi.org/10.1073/pnas.1522149113.

44. Alm EW, Oerther DB, Larsen N, Stahl DA, Raskin L. The oligonucleotide probe database. Appl Environ Microbiol. 1996;62(10):3557-9.

45. Song Y, Liu C, McTeague M, Vu A, Liu JY, Finegold SM. Rapid identification of Gram positive anaerobic coccal species originally classified in the genus Peptostreptococcus by multiplex PCR assays using genus- and speciesspecific primers. Microbiology. 2003;149(7):1719-27. https://doi.org/10.1099/ mic. $0.26227-0$.

46. Santos R, Gomes D, Macedo H, Barros D, Tibério C, Veiga AS, Tavares L, Castanho M, Oliveira M. Guar gum as a new antimicrobial peptide delivery system against diabetic foot ulcers Staphylococcus aureus isolates. J Med Microbiol. 2016;65:1092-9. https://doi.org/10.1099/jmm.0.000329.

\section{Publisher's Note}

Springer Nature remains neutral with regard to jurisdictional claims in published maps and institutional affiliations.

Ready to submit your research? Choose BMC and benefit from:

- fast, convenient online submission

- thorough peer review by experienced researchers in your field

- rapid publication on acceptance

- support for research data, including large and complex data types

- gold Open Access which fosters wider collaboration and increased citations

- maximum visibility for your research: over $100 \mathrm{M}$ website views per year

At BMC, research is always in progress.

Learn more biomedcentral.com/submissions 